\title{
THE PHARMACOKINETICS OF THIAMPHENICOL IN LACTATING COWS
}

\author{
N. MESTORINO, M.F. LANDONI, M. ALT AND J.O. ERRECALDE \\ Cátedra de Farmacología, Farmacotecnia y Terapéutica, Facultad de Ciencias \\ Veterinarias, Universidad Nacional de La Plata, Calle 60 y 118, cc 296 (1900) La \\ Plata, Argentina
}

\section{ABSTRACT}

Mestorino, N., Landoni, M.F., Alt, M. and Errecalde, J.O., 1993. The pharmacokinetics of thiamphenicol in lactating cows. Veterinary Research Communications, 17 (4), 295-303

\begin{abstract}
The pharmacokinetics of thiamphenicol were studied after intravenous and intramuscular administration of $25 \mathrm{mg} / \mathrm{kg}$ body weight in lactating cows. Distribution $\left(t_{16}\right)$ and elimination $\left(t_{\text {tr }}\right)$ half-lives of $6.10 \pm 1.39 \mathrm{~min}$ and $1.60 \pm 0.30 \mathrm{~h}$, respectively, were obtained after intravenous administration. The body clearance was $3.9 \pm 0.077 \mathrm{ml} / \mathrm{kg}$ per min and the apparent volume of distribution was $1220.79 \pm 256.67 \mathrm{ml} / \mathrm{kg}$. The rate at which thiamphenicol appeared in the milk, as indicated by the penetration half-life $\left(t_{1}\right)$ (serum to quarters), was found to be $36.89 \pm 11.14 \mathrm{~min}$. The equivalent elimination half-life ( $t$ ( $/ \mathrm{f})$ (quarters to serum) from the milk was $3.62 \pm 1.06 \mathrm{~h}$ and the peak thiamphenicol concentration in the milk was $23.09 \pm 3.42 \mu \mathrm{g} / \mathrm{ml}$ at $2.5 \pm 0.32 \mathrm{~h}$.

After intramuscular injection, the elimination half-life was $2.2 \pm 0.40 \mathrm{~h}$, the absorption half-life was $4.02 \pm 1.72 \mathrm{~min}$ and the peak concentration in the serum was $30.90 \pm 5.24 \mu \mathrm{g} / \mathrm{ml}$ at $23 \pm 8.4 \mathrm{~min}$. The bioavailability after intramuscular administration approached $100 \%$. The penetration half-life was $50.59 \pm 6.87 \mathrm{~min}$, the elimination half-life was $5.91 \pm 4.97 \mathrm{~h}$ and the mean peak concentration in the milk was $17.37 \pm 2.20 \mu \mathrm{g} / \mathrm{ml}$ at $3.4 \pm 0.22 \mathrm{~h}$.
\end{abstract}

Keywords: cows, intramuscular, intravenous, lactation, milk, pharmacokinetics, serum, thiamphenicol

Abbreviations: AUC, area under the concentration-time curve; CAP, chloramphenicol; $C$, peak concentration; IM, intramuscular; IV, intravenous; TAP, thiamphenicol; $t$, distribution haxlf-life; $t_{1 / 2 B}$, elimination half-life; $V_{\mathrm{c}}$, volume of central compartment; $V_{\mathrm{d}}$, volume of disfribution

\section{INTRODUCTION}

The toxicity of chloramphenicol has been the cause of its use being banned or strictly regulated worldwide. This has accentuated the need for an effective broad-spectrum antibiotic to be used in food-animal medicine. Thiamphenicol is a structural analogue of CAP with marked toxicological differences (see comparative structures in Figure 1). TAP has a greater in vitro activity against pathogenic bacteria than either of its structural analogues. It is active against some bacteria that are resistant to CAP (Neu and $\mathrm{Fu}, 1980$ ).

CAP has been reported to cause reversible, dose-related bone marrow suppression in humans by a mechanism involving inhibition of mitochondrial protein synthesis (Yunis, 1981). It also causes irreversible non-dose-related aplastic anaemia in humans by a mechanism that is not well understood (Yunis, 1981).

TAP is a bacteriostatic/bactericidal antibiotic with the same mode of action as CAP. Reversible, dose-dependent bone marrow suppression caused by inhibition of 
mitochondrial protein synthesis is also a side-effect of TAP (Yunis et al., 1973; Keiser, 1974) but an irreversible aplastic anaemia has not been reported following the use of this drug (Yunis et al., 1973; Ferrari and Pajola, 1981). The fact that the $p$-methylsulphonyl group in TAP has replaced the $p$-nitro group on the aromatic ring of CAP (see Figure 1) gives support to the hypothesis that the $p$-nitro group of CAP is responsible for the aplastic anaemia.
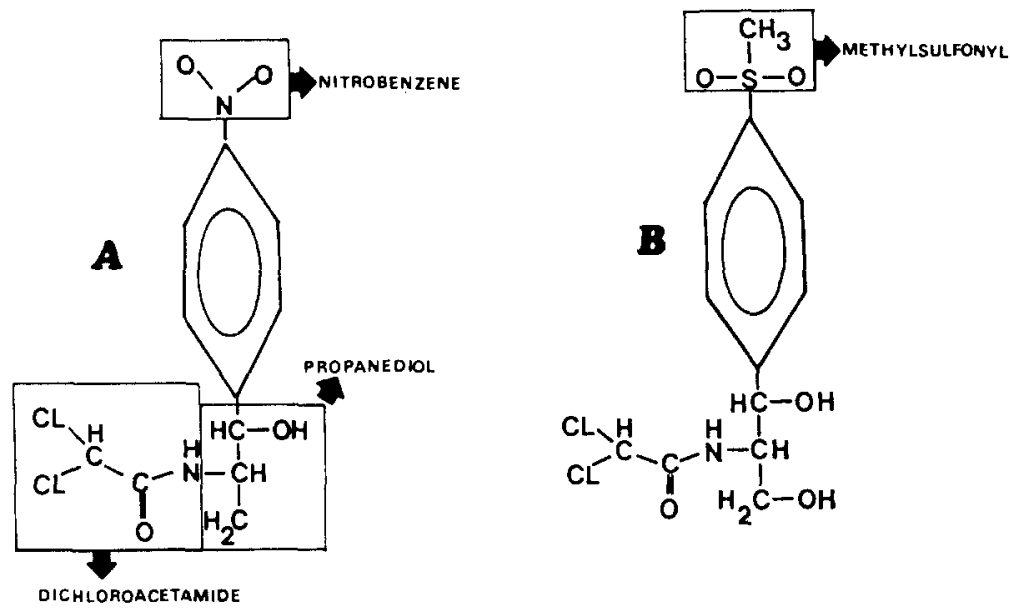

Figure 1. Structural formulae of chloramphenicol (A) and thiamphenicol (B)

Although TAP has a similar antibacterial spectrum to that of CAP (Van Beers $e t$ al., 1975), there are marked pharmacological differences between the two drugs. Thus, TAP is more stable in solution (Azzolini et al., 1970), is not appreciably protein bound in the body and does not undergo significant biotransformation (Azzolini et al., 1970). The drug diffuses into intracellular spaces, the central nervous system and the aqueous humour (Huber, 1965).

In view of the limited kinetic data available on this antibiotic in ruminants, we decided to investigate the disposition kinetics of TAP after a rapid single intravenous injection in cows and to compare these data with those obtained after intramuscular administration of an equal dose in the same animals.

\section{MATERIALS AND METHODS}

Six healthy lactating Holstein cows (weighing $468 \pm 54.05 \mathrm{~kg}$ ) each received single doses of $25 \mathrm{mg} / \mathrm{kg}$ thiamphenicol glycinate chlorhydrate $(26.66 \%$ solution in phosphate buffer, $\mathrm{pH}$ 6) by both the intravenous and the intramuscular routes following a $3 \times 3$ cross-over design. Three weeks elapsed between injections. The drug was administered IV in the right jugular vein. For IM administration, half the volume was injected into each ischiotibial muscle zone.

Blood samples were drawn through a polyethylene catheter placed in the left jugular vein. Samples were taken immediately before the injection (control) and at the 
following times after injection: 5, 10, 15 and 30 min and 1, 1.5, 2, 3, 4, 5, 6, 8, 10 and 12 h. After clotting, the serum was separated by centrifugation and stored at $-20^{\circ} \mathrm{C}$ until assayed. Milk samples were collected from the left front quarter through a teat catheter immediately before the injection (control) and at 5, 10, 15, 30 and $40 \mathrm{~min}$ and $1,1.5,2,2.5,3,3.5,4,5,6,8,10$ and $12 \mathrm{~h}$ after injection. The milk samples were kept at $-20^{\circ} \mathrm{C}$ until assayed. TAP concentrations were determined microbiologically by a modified cylinder-plate diffusion method (Grove and Randall, 1955). The test organism was Sarcina lutea ATCC 9341 and the culture medium was antibiotic medium number 1 (Difco Laboratories, Detroit, MI, USA). The sensitivity of the assay was $5 \mu \mathrm{g} / \mathrm{ml}$ of serum or milk. The average of four replicates of each sample was compared with a standard curve produced from bovine serum containing known amounts of thiamphenicol. The same procedure was adopted for assay of the milk samples.

The pharmacokinetic models that best fitted the TAP plasma profiles after both IV and IM administration were derived by means of the MAICE (Minimum Akaike Information Criterion) Test (Akaike, 1976; Yamaoka et al., 1978).

The means and standard deviations were calculated for the thiamphenicol concentrations in serum and milk at the various times. The pharmacokinetic parameters were estimated for each cow by weighted least-squares non-linear regression employing a package of programs known as ADAPT (D'Argenio and Schumitzky, 1979), which uses the Simplex algorithm (Nelder and Mead, 1965). The bioavailability of thiamphenicol administered by the IM route (defined by $F$, the absorbed fraction) was obtained as the ratio between the areas under the curves of concentration versus time after IV and IM administrations. The areas under the blood or milk curves for concentration versus time were calculated by the trapezoidal rule (Baggot, 1978).

The withdrawal time $(T)$ for milk following intramuscular administration was calculated by employing the formula reported by Nouws and Ziv (1978) modified as follows:

$$
T=\frac{t_{1 / 2}\left[\ln R \cdot C_{\max }-\ln C_{\lim }\right]}{\ln 2}
$$

where $t_{1 / 2}$ is the biological or disposition half-life, $C_{\max }$ is the peak plasma TAP concentration, and $R$ is the milk:plasma ratio of the TAP concentration. $C_{\lim }$ represents the maximum permitted residue level of $20 \mathrm{ng} / \mathrm{ml}$, as recommended by Boisseau (1985).

\section{RESULTS}

The TAP concentration-time profiles for serum and milk after IV and IM administration of $25 \mathrm{mg} / \mathrm{kg}$ are shown in Figures 2 and 3, respectively. The mean pharmacokinetic parameters corresponding to the IV and IM routes in serum and milk are given in Tables I and II, respectively.

In the case of IV administration, the disappearance of TAP from the blood was clearly a two-rate phenomenon and this was confirmed by the MAICE Test. 


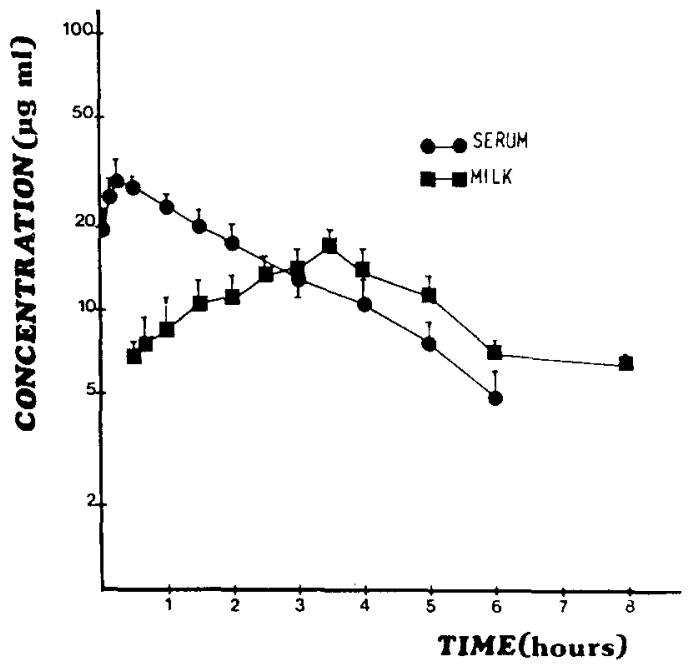

Figure 2. Semilogarithmic plots of averaged serum and milk thiamphenicol concentrations for six lactating cows following intravenous administration of $25 \mathrm{mg}$ thiamphenicol $/ \mathrm{kg}$ body mass

A one-compartment pharmacokinetic model with first-order absorption was selected by means of the MAICE Test to describe the serum disposition of TAP after IM administration to lactating cows.

The other parameters indicate a liposoluble drug with a high volume of distribution and penetration into milk.

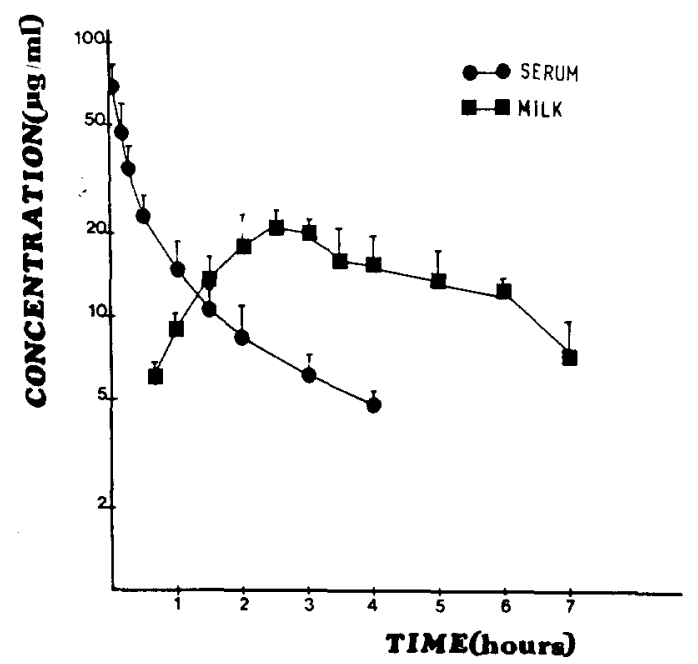

Figure 3. Semilogarithmic plots of averaged serum and milk thiamphenicol concentrations for six lactating cows following intramuscular administration of $25 \mathrm{mg}$ thiamphenicol $/ \mathrm{kg}$ body mass 


\section{TABLE I}

Mean pharmacokinetic parameters in serum determined for six lactating cows after intravenous and intramuscular administration of $25 \mathrm{mg}$ thiamphenicol $/ \mathrm{kg}$ body mass

\begin{tabular}{|c|c|c|}
\hline \multirow[b]{2}{*}{ Parameter $^{\mathbf{a}}$} & \multicolumn{2}{|c|}{ Administration route } \\
\hline & $I V^{b}$ & $\mathrm{IM}^{\mathrm{b}}$ \\
\hline$A(\mu \mathrm{g} / \mathrm{ml})$ & $86.15 \pm 55.05$ & - \\
\hline$\alpha\left(\mathrm{h}^{-1}\right)$ & $7.06 \pm 1.32$ & - \\
\hline$t_{1 / 2 \alpha}(\min )$ & $6.10 \pm 1.39$ & - \\
\hline$B(\mu \mathrm{g} / \mathrm{ml})$ & $23.26 \pm 5.39$ & - \\
\hline$\beta\left(\mathrm{h}^{-1}\right)$ & $0.45 \pm 0.09$ & $0.32 \pm 0.07$ \\
\hline$t_{1 / 2 B}(\mathrm{~h})$ & $1.6 \pm 0.30$ & $2.2 \pm 0.40$ \\
\hline$K_{\mathrm{ab}}^{20}\left(\mathrm{~h}^{-1}\right)$ & - & $12.52 \pm 6.75$ \\
\hline$t_{1 / 2 \mathrm{ab}}^{\mathrm{au}}(\mathrm{min})$ & - & $4.02 \pm 1.72$ \\
\hline$C_{0}(\mu \mathrm{g} / \mathrm{ml})$ & $109.40 \pm 53.37$ & - \\
\hline$V_{\mathrm{c}}(\mathrm{ml} / \mathrm{kg})$ & $268.00 \pm 0.13$ & - \\
\hline$K_{12}\left(\mathrm{~h}^{-1}\right)$ & $3.66 \pm 0.94$ & - \\
\hline$K_{21}\left(\mathrm{~h}^{-1}\right)$ & $2.06 \pm 0.86$ & - \\
\hline$K_{\mathrm{el}}^{21}\left(\mathrm{~h}^{-1}\right)$ & $1.81 \pm 0.93$ & - \\
\hline AUC $(\mu \mathrm{g} \cdot \mathrm{h} / \mathrm{ml})$ & $47.89 \pm 7.60$ & $65.71 \pm 14.16$ \\
\hline$C l_{\mathrm{B}}(\mathrm{ml} / \mathrm{kg}$ per min $)$ & $3.90 \pm 0.077$ & - \\
\hline$V_{\mathrm{d}}^{\mathrm{D}}($ area $)(\mathrm{ml} / \mathrm{kg})$ & $1220.79 \pm 256.67$ & - \\
\hline$C_{\max }(\mu \mathrm{g} / \mathrm{ml})$ & - & $30.90 \pm 5.24$ \\
\hline$T_{\max }^{\max }(\min )$ & - & $23.00 \pm 8.40$ \\
\hline Lag-obs (min) & - & 5.00 \\
\hline$F(\%)$ & & $100.33 \pm 22.82$ \\
\hline
\end{tabular}

${ }^{\mathrm{a}} A$ and $B$ are $y$-axis intercepts of regression lines best fitting distribution and elimination data points respectively; $\alpha$ and $\beta$ are distributive and eliminative rate constants, and $t_{1 / 2 \alpha}$ and $t_{1 / 2 \beta}$ their respective half-lives; AUC is the area under the serum concentration-time curve; $V_{c}$ is the apparent volume of the central compartment, and $V_{\mathrm{d}}$ (area) is the apparent volume of distribution calculated by the area method; $\mathrm{Cl}_{\mathrm{B}}$ is the body clearance; $K_{12}, K_{21}$ and $K_{\mathrm{el}}$ are microconstants associated with the two-compartment pharmacokinetic model; $K_{\mathrm{ab}}$ is the absorption rate constant and $t_{1 / 2 a b}$ its half-life; Lag-obs is the interval between drug administration and its detection in serum; $C_{\max }$ is the maximum observed serum concentration and $T_{\max }$ is the time at which the maximum concentration occurred; $F$ is bioavailability

${ }^{\mathrm{b}}$ Values are mean $\pm \mathrm{SD}$ 


\section{TABLE II}

Mean pharmacokinetic parameters in milk determined for six lactating cows after intravenous and intramuscular administration of $25 \mathrm{mg}$ thiamphenicol/ $\mathrm{kg}$ body mass

\begin{tabular}{lcc}
\hline & \multicolumn{2}{c}{ Administration route } \\
\cline { 2 - 3 } Parameter $^{\mathrm{a}}$ & $\mathrm{IV}^{\mathrm{b}}$ & $\mathrm{IM}^{\mathrm{b}}$ \\
\hline$B(\mu \mathrm{g} / \mathrm{ml})$ & $33.44 \pm 12.39$ & $25.14 \pm 8.40$ \\
$K_{\mathrm{e}}\left(\mathrm{h}^{-1}\right)$ & $0.21 \pm 0.067$ & $0.16 \pm 0.07$ \\
$t_{1 / 2 \mathrm{E}}(\mathrm{h})$ & $3.62 \pm 1.06$ & $5.91 \pm 4.97$ \\
$K_{\mathrm{p}}\left(\mathrm{h}^{-1}\right)$ & $1.23 \pm 0.41$ & $0.83 \pm 0.11$ \\
$t_{1 / \mathrm{P}}(\min )$ & $36.89 \pm 11.14$ & $50.59 \pm 6.87$ \\
$C_{\max } \mathrm{M}(\mu \mathrm{g} / \mathrm{ml})$ & $23.09 \pm 3.42$ & $17.37 \pm 2.20$ \\
$T_{\max } \mathrm{M}(\mathrm{h})$ & $2.5 \pm 0.32$ & $3.4 \pm 0.22$ \\
$C_{\max }^{\operatorname{Sim}: C_{\max } \mathrm{Mim}}$ & - & $1.88 \pm 0.58$ \\
AUC $(\mu \mathrm{g} \cdot \mathrm{h} / \mathrm{ml})$ & $85.22 \pm 24.55$ & $0.92 \pm 0.20$ \\
AUC M:AUC S & $1.81 \pm 0.56$ & $52.54 \pm 17.11$ \\
Withdrawal (h) & - & \\
& & \\
\hline
\end{tabular}

${ }^{\mathrm{a}} K_{\mathrm{e}}$ is the elimination-from-milk rate constant and $t_{\mathrm{y} / \mathrm{E}}$ its half-life; $K_{\mathrm{p}}$ is the penetration-in-milk rate constant and $t_{1 / 2}$ its half-life; $C_{\max } \mathrm{M}$ is the $C_{\max }{ }_{\mathrm{p}}$ in milk; $C_{\max } \operatorname{Sim}: C_{\max }$ Mim is the ratio between the $C_{\max }$ in serum and $C_{\max }$ in milk after IM administration; AUC is area under the curve; AUC M:AUC $S$ is the ratio between AUC concentration vs time in serum and milk after IV and IM administration; Withdrawal is the withdrawal time needed to obtain milk with TAP levels of less than $20 \mathrm{ng} / \mathrm{ml}$

${ }^{\mathrm{b}}$ Values are mean $\pm \mathrm{SD}$

\section{DISCUSSION}

For IV administration, the distribution half-life of TAP of $6.10 \pm 1.39 \mathrm{~min}$ from the central compartment was slightly shorter than those reported for CAP in cows of 9.6 min (Burrows et al., 1978) and 11.5 min (Anderson et al., 1983), or those for florfenicol of $7.94 \mathrm{~min}$ in male veal calves (Adams et al., 1987) and $12.6 \mathrm{~min}$ in lactating cows (Signorini et al., 1986). However, a lower value of $1.84 \mathrm{~min}$ was reported for CAP in swine (Mercer et al., 1978). These differences may have arisen because of the early blood samples taken in the present work.

The mean volume of the central compartment was $268 \pm 0.13 \mathrm{ml} / \mathrm{kg}$, a value that is comparable with that of $361 \mathrm{ml} / \mathrm{kg}$ reported for CAP in calves (Burrows et al., 1978) but smaller than that of $920 \mathrm{ml} / \mathrm{kg}$ reported in cows (Van Der Lee et al., 1982). The mean apparent volume of distribution of $1220.79 \pm 256.67 \mathrm{ml} / \mathrm{kg}$ obtained by the area method was relatively large. This value correlates with the high lipid solubility of TAP, suggesting excellent penetration and distribution of the drug in the body fluids, including the intracellular water. Similar values were reported by Signorini and 
colleagues (1986) $(1440 \mathrm{ml} / \mathrm{kg})$ in the same kind of animals, by Burrows and colleagues (1978) for CAP in young calves $(1264 \mathrm{ml} / \mathrm{kg}$ ) and by Anderson and colleagues (1983) in adult cows $(1110 \mathrm{ml} / \mathrm{kg})$. In old lactating cows, however, a value of $2900 \mathrm{ml} / \mathrm{kg}$, more than double that reported here was found by Van Der Lee and colleagues (1978). Although those authors did not discuss this point, it is possible that this reported increase in $V_{d}$ in older animals may be attributed to the fact that such animals have less total body water than younger animals: as a consequence there could be a diminution of $V_{c}$ and an increase in $V_{\mathrm{d}}$.

The elimination half-life of $1.6 \pm 0.30 \mathrm{~h}$ indicates that cows eliminate TAP rapidly. Our value is smaller than the mean value of $2.57 \mathrm{~h}$ reported by Signorini and colleagues (1986), who did not specify the vehicle used, that of 3.45-4.11 h reported for florfenicol in male veal calves, with no specification as to age or weight, by Adams and colleagues (1987), that of $3.5 \mathrm{~h}$ reported in cattle by Pilloud (1973), and those of $11.7 \mathrm{~h}$ and $4.9 \mathrm{~h}$ reported for CAP in day-old and 10- to 12-week-old calves by Reiche and colleagues (1980). The longer half-life reported in neonatal calves could be due to their underdeveloped hepatic drug-metabolizing enzyme systems. For the $3.5 \mathrm{~h}$ reported by Pilloud, we have no explanation other than that 3 of the 5 experimental animals were in late pregnancy. For a liposoluble drug like CAP, extensive distribution in the pregnant uterus and fetus might contribute to retarding the elimination process.

The total body clearance for TAP $(3.9 \pm 0.077 \mathrm{ml} / \mathrm{kg}$ per min $)$ agrees with the value of $3.9 \mathrm{ml} / \mathrm{kg}$ per min reported by Signorini and colleagues (1986) in cows. However, a slightly lower value was reported for CAP in 7-day-old calves $(1.9 \mathrm{ml} / \mathrm{kg}$ per min) (Reiche et al., 1980).

Following IV administration of $25 \mathrm{mg} / \mathrm{kg}$ of TAP, the drug concentration in serum at $5 \mathrm{~min}$ was $68.54 \pm 24.58 \mu \mathrm{g} / \mathrm{ml}$ and a concentration exceeding $4 \mu \mathrm{g} / \mathrm{ml}$ persisted for about $4 \mathrm{~h}$.

Therapeutic levels of TAP ( $\geqslant 5 \mu \mathrm{g} / \mathrm{ml}$ ) were maintained in the milk for between $40 \mathrm{~min}$ and $8 \mathrm{~h}$ after IV administration. These data compare well with the value of between 2 and $8 \mathrm{~h}$ reported for CAP in cows (Sisodia et al., 1973). The elimination half-life from the milk of $3.62 \pm 1.06 \mathrm{~h}$ indicates that accumulation of TAP takes place in the mammary gland. This could be explained by the marked affinity of TAP for lipids. This fact must be carefully considered when calculating milk withdrawal times.

The ratio of AUC in milk to AUC in serum of $1.81 \pm 0.56$ suggests extensive penetration of TAP into the mammary gland. This agrees with the mammary accumulation data (Table II).

Thiamphenicol administered IM was absorbed rapidly and completely. The mean half-life of absorption of $4.02 \pm 1.72 \mathrm{~min}$ was much shorter than that of $30 \mathrm{~min}$ reported for CAP in cows (Nouws and Ziv, 1979; Archimbault et al., 1980). The interval between administration of the drug and its detection in serum was only 5 min and the peak serum concentration was achieved after about $23 \mathrm{~min}$. The early and intensive sampling scheme used in our work may have contributed to a better definition of the absorptive phase and a smaller estimate for the half-life of absorption.

The mean intramuscular bioavailability of about $100 \%$ was similar to values reported for various formulations of CAP in cattle (Archimbault et al., 1980; Reiche $e t$ al., 1980) and that reported for TAP by Signorini and colleagues (1986). This finding 
is in agreement with the high lipophilicity of the drug. The elimination half-life of 2.2 $\pm 0.40 \mathrm{~h}$ was similar to that of 2.29 reported by Signorini and colleagues (1986) but much shorter than the mean values of $13.9 \mathrm{~h}$ reported for CAP in cows (Guillot and Mourot, 1987) and $10.3 \pm 3.1 \mathrm{~h}$ reported in cattle (Nouws et al., 1986). These differences may be due to the characteristics of the formulation, since in the present study the vehicle used was phosphate buffer, whereas the other workers used unspecified organic vehicles that may have modified the absorption profile and, as a consequence, the elimination half-life.

Therapeutic levels of TAP $(\geqslant 5 \mu \mathrm{g} / \mathrm{ml})$ were maintained in milk for between 30 min and $8 \mathrm{~h}$ after IM administration. The increased milk $t_{1 / 2}$ of $5.91 \pm 4.97 \mathrm{~h}$ as compared with the $t_{1 / 2 \beta}$ for serum may be explained in the same way as for IV administration, namely by mammary gland accumulation. The high lipid contents of milk and of the mammary gland could clearly induce some trapping of TAP, with rapid penetration and slow elimination. The ratios of the elimination half-life $\left(t_{1 / 2}\right)$ in milk to that $\left(t_{1 / 2 \beta}\right)$ in serum were 2.26 and 2.69 for intravenous and intramuscular injections, respectively.

Rapid penetration from blood into milk after IM administration is characterized by the drug having a short appearance time in the milk (Ziv, 1978), with a ratio of $C_{\max }$ in serum to $C_{\max }$ in milk of 2 or less, a very short lag time between $C_{\max }$ serum and $C_{\max }$ milk, and a ratio of AUC in milk to AUC in serum of 1 or more. TAP fulfils all these requirements and is clearly a drug that penetrates easily into milk.

The average withdrawal time to obtain a concentration of $20 \mathrm{ng} / \mathrm{ml}$ was $52.54 \pm$ $17.11 \mathrm{~h}$.

In summary, it has been shown that TAP, a broad-spectrum antibiotic, has advantageous phamacokinetic properties for treating cows. From the serum concentrations (Figures 2 and 3) and pharmacokinetic information it can be concluded that, depending on the minimum inhibitory concentration for the microorganisms involved, three treatments per day would be effective in treating susceptible infections and might be recommended where no other effective antibiotic with a narrower spectrum was available.

\section{REFERENCES}

Adams, P.E., Varma, K.J. and Powers, T.E., 1987. Tissue concentrations and pharmacokinetics of florfenicol in male veal calves given repeated doses. American Journal of Veterinary Research, 48, $1725-1732$

Akaike, H., 1976. An information criterion (AIC). Mathematical Science, 14 (153), 5-9

Anderson, K.L., Neff-Davis, C.A., Davis, L.E., Koritz, B.D. and Nelson, D.R., 1983. Pharmacokinetics of chloramphenicol in non-lactating cattle. Journal of Veterinary Pharmacology and Therapeutics, 6 , $305-313$

Archimbault, P., Boutier, C. and Fellous, R., 1980. Concentrations sériques et biođisponibilité sanguine de chloramphenicol chez les bovins. Canadian Veterinary Journal, 21, 323-327

Azzolini, F., Gazzaniga, A. and Lodola, E, 1970. Thiamphenicol excretion in subjects with renal insufficiency. International Journal of Clinical Pharmacology, Therapeutics and Toxicology, 4, 303-308

Baggot, J.D., 1978. Some aspects of clinical pharmacokinetics in veterinary medicine II. Journal of Veterinary Pharmacology and Therapeutics, 1, 111-118

Boisseau, J., 1985. Le chloramphenicol en médicine vétérinaire, les conditions d'autorisation de mise sur le marché. Annales de Recherche Vétérinaire, 16, 155-157

Burrows, G.E., Barto, P.B. and Weeks, B.R., 1978. Chloramphenicol, lincomycin and oxytetracycline disposition in calves with experimental pneumonic pasteurellosis. Journal of Veterinary Pharmacology and Therapeutics, 9, 213-222 
D'Argenio, D.Z. and Schumitzky, A., 1979. A programme package for simulation and parameter estimation. Pharmacokinetics Systems Computer Programs in Biomedicine, 9, 115-134

Ferrari, V. and Pajola, E., 1981. Types of haemopoietic inhibition by chloramphenicol and thiamphenicol. In: J. Najean et al. (eds.), Safety Problems Related to Chloramphenicol and Thiamphenicol Therapy, (Raven Press, New York), 43-59

Grove, D.C. and Randall, W.A., 1955. Assay Methods of Antibiotics, (Medical Encyclopedia Inc., New York)

Guillot, P. and Mourot, D., 1987. Biodisponibilité de 3 spécilités commerciales de chloramphenicol chez les bovins adultes. Influence du volume injecté et du nombre de points du injection. Recueil de Medicine Véterinaire, $163,49-52$

Huber, W.G., 1965. Chloramphenicol and other antibacterial substances. In: L.M. Jones (ed.), Veterinary Pharmacology and Therapeutics, 3rd edn, (Iowa State University Press, Ames, IA)

Keiser, G., 1974. Co-operative study of patients treated with thiamphenicol. Comparative study of patients treated with chloramphenicol and thiamphenicol. Postgraduate Medical Journal, 50 (suppl 5), 143-145

Mercer, H.D., Heath, G.E., Long, P.E. and Powers, T.E., 1978. Drug residues in food animals. I. Plasma and tissue kinetics of chloramphenicol in young cross-bred swine. Journal of Veterinary Pharmacology and Therapeutics, 1, 19-36

Nelder, J. and Mead, R., 1965. A simplex method for function minimization. Computers Journal, 4, 308-313

Neu, H.C. and Fu, K.P., 1980. In vitro activity of chloramphenicol and thiamphenicol analogs. Antibacterial Agents and Chemotherapy, 18, 311-316

Nouws, J.F.M. and Ziv, G., 1978. Pre-slaughter withdrawal times for drug in dairy cows. Joumal of Veterinary Phamacology and Therapeutics, 1, 47-56

Nouws, J.F.M. and Ziv, G., 1979. Serum chloramphenicol levels and the intramuscular bioavailability of several parenteral formulations of chloramphenicol in ruminants. The Veterinary Quarterly, 1, 46-58

Nouws, J.F.M., Vree, T.B., Holtkamp, J., Baakman, M., Driessens, F. and Guelen, P.J.M., 1986. Pharmacokinetic, residue and irritation aspects of chloramphenicol sodjum succinate and a chloramphenicol base formulation following intramuscular administration to ruminants. The Veterinary Quarterly, 8, 224-232

Pilloud, M., 1973. Pharmacokinetics, plasma protein binding and dosage of chloramphenicol in cattle and horses. Research in Veterinary Science, 15, 231-238

Reiche, R., Mulling, M. and Frey, H.H., 1980. Pharmacokinetics of chloramphenicol in calves during the first week of life. Joumal of Veterinary Pharmacology and Therapeutics, 3, 95-106

Signorini, G.C., Bonanomi, L., Longo, A. and Mondellini, A., 1986. Farmacocinetica Ematica del Tiamfenicolo nel Bovino. (Istituto di Clinic Médic Veterinaria Universitá di Parma, Laboratori Ricerche Zambon Farmaceutici S.p.A. Bresso, Milano), 311-315

Sisodia, C.S., Guptak, V.S., Dunlop, R.H. and Radostits, O.M., 1973. Chloramphenicol concentrations in blood and milk of cows following parenteral administration. Canadian Veterinary Journal, 14, 217-220

Van Beers, D., Schoutens, E., Vandeerlinden, M.P. and Yourrassowky, E., 1975. Comparative in vitro activity of chloramphenicol and thiamphenicol on common aerobic and anaerobic gram-negative bacilli (Salmonella and Shigella excluded). Chentotherapy, 21, 73-81

Van Der Lee, J.J., Nouws, J.F.M. and Bloemendal, F.W.R., 1982. Physicochemical methods for pharmacokinetic and residue analysis of chloramphenicol and degradation products in dairy cows. Journal of Veterinary Pharmacology and Therapeutics, 5, 161-175

Yamaoka, K., Nakagawa, T. and Uno, T., 1978. Application of Akaike's information criterion (AIC) in the evaluation of linear pharmacokinetic equations. Journal of Pharmacokinetics and Biopharmaceutics, $\mathbf{6}$, $165-175$

Yunis, A.A., 1981. Chloramphenicol toxicity and the role of the $p$-NO in aplastic anemia. In: J. Najean et al. (eds.), Safety Problems Related to Chloramphenicol and Thiamphenicol Therapy, (Raven Press, New York), $17-30$

Yunis, A.A., Manyan, D.R. and Arimura, G.K., 1973. Comparative effect of chloramphenicol and thiamphenicol on DNA and mitochondrial protein synthesis in mammalian cells. Journal of Laboratory Clinical Medicine, 81, 713-718

Ziv, G., 1978. Practical pharmacokinetic aspects of mastitis therapy. In: Proceedings of the Bovine Mastitis Regional Seminar, April 1978 (School of Veterinary Medicine, University of California, Davis), 1-52 